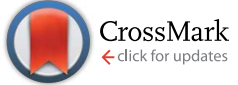

Cite this: RSC Adv., 2015, 5, 26991

Received 5th March 2015

Accepted 12th March 2015

DOI: $10.1039 / \mathrm{c} 5 \mathrm{ra03963k}$

www.rsc.org/advances

\section{Characterization of phenolic compounds and antioxidant properties of Glycyrrhiza glabra L. rhizomes and roots}

\author{
Natália Martins, ${ }^{\text {ab }}$ Lillian Barros, ${ }^{* a}$ Montserrat Dueñas, ${ }^{c}$ Celestino Santos-Buelga ${ }^{c}$ \\ and Isabel C. F. R. Ferreira*a
}

The present work aims to characterize and quantify the phenolic composition and to evaluate the antioxidant activity of Glycyrrhiza glabra L. (commonly known as licorice) rhizomes and roots. The antioxidant potential of its methanol/water extract could be related to flavones (mainly apigenin derivatives), flavanones (mainly liquiritin derivatives), a methylated isoflavone and a chalcone, identified in the extract. Lipid peroxidation inhibition was the most pronounced antioxidant effect $\left(E_{50}=0.24 \pm\right.$ $0.01 \mu \mathrm{g} \mathrm{mL} \mathrm{m}^{-1}$ and $22.74 \pm 2.42 \mu \mathrm{g} \mathrm{mL} \mathrm{m}^{-1}$ in TBARS and $\beta$-carotene/linoleate assays, respectively), followed by free radical scavenging activity $\left(\mathrm{EC}_{50}=111.54 \pm 6.04 \mu \mathrm{g} \mathrm{mL}^{-1}\right)$ and, finally, reducing power $\left(E C_{50}=128.63 \pm 0.21 \mu \mathrm{g} \mathrm{mL}^{-1}\right)$. In this sense, licorice extract could be used as a source of antioxidants for the pharmaceutical, cosmetic and/or food industries.

\section{Introduction}

Environmental factors, such as pollution, smoking, certain drugs, poor diet, sedentary lifestyle and stress-inducing agents, are considered the main external aggressors for human bodies, increasing cell deterioration and, in the long term, contributing to aging and several diseases/disorders. Furthermore, the normal metabolism also produces high quantities of oxidant molecules, through different chemical reactions. Commonly known as free radicals, these substances are highly reactive molecules containing one or more unpaired electrons in atomic or molecular orbitals that can join with cellular components and destroy them. ${ }^{\mathbf{1 - 3}}$

Plants are widely used to improve health and even to treat various diseases. Currently, there are several studies evidencing these natural matrices as rich sources of biomolecules, which provide numerous health benefits. ${ }^{4-6}$ Antioxidant phytochemicals are a good example of these biomolecules, being considered important contributors to protect cells and DNA, once neutralize reactive molecules and even prevent a cascade of reactions that lead to degenerative processes such as aging, neurodegenerative diseases, cancer, cardiovascular

${ }^{a}$ Mountain Research Centre (CIMO), ESA, Polytechnic Institute of Bragança, Campus de Santa Apolónia, Apartado 1172, 5301-855 Bragança, Portugal. E-mail: iferreira@ ipb.pt; lillian@ipb.pt; Fax: +351-273-325405; +351-273-325405; Tel: +351-273303219; +351-273-303903

${ }^{b}$ CEB, Centre of Biological Engineering, LIBRO - Laboratório de Investigação em Biofilmes Rosário Oliveira, University of Minho, 4710-057 Braga, Portugal

${ }^{c}$ GIP-USAL, Faculty of Pharmacy, University of Salamanca, Campus Miguel de Unamuno, 37007 Salamanca, Spain diseases, cataracts, rheumatism, ulcers, or atherosclerosis, among others. ${ }^{1,2,7-11}$

Among antioxidants, phenolic compounds have been considered important promoters of health and wellbeing, acting as free radical scavengers, metal chelators, singlet oxygen quenchers, inhibitors of lipid peroxidation as well as modulators of the formation of pro-oxidant and pro-inflammatory molecules (leukotrienes, 5-LOX, cytokines). ${ }^{\mathbf{1 2 - 1 4}}$

Glycyrrhiza glabra L. (Fabaceae), commonly known as licorice, is widely recommended as emollient, for upper respiratory tract infections and dermal affections, as anti-inflammatory, antiulcer, antibacterial, antifungal, antiviral, anti-allergic, and immunostimulant, among other benefits. ${ }^{15-18}$ Its antioxidant properties have also been reported, either in aqueous, ${ }^{7,19,20}$ ethanol,,$^{20-22}$ methanol ${ }^{20,23-25}$ or methanol/water ${ }^{26,27}$ extracts. There are several studies that focused on the phenolic characterization of Glycyrrhiza sp..$^{23,24,26,27}$ Nevertheless, information on the quantification of these compounds is scarce.

The aim of this work was to characterize and quantify the phenolic composition and evaluate the antioxidant properties in methanol/water extracts of Glycyrrhiza glabra L. (rhizomes and roots).

\section{Materials and methods}

\subsection{Samples}

Dried rhizomes and roots of Glycyrrhiza glabra L. were supplied by Soria Natural (Garray - Soria, Spain). The samples were obtained in the autumn 2012 and certified as clean products, with monitored parameters for pesticides, herbicides, heavy 
metals and radioactivity. For each analysis, three different samples were used and the assays were performed in triplicate.

\subsection{Standards and reagents}

Methanol was of analytical grade purity and supplied by Pronalab (Lisbon, Portugal). 2,2-Diphenyl-1-picrylhydrazyl (DPPH) was obtained from Alfa Aesar (Ward Hill, MA, USA). HPLC-grade acetonitrile was obtained from Merck KgaA (Darmstadt, Germany). Formic and acetic acids were purchased from Prolabo (VWR International, France). The phenolic compound standards were from Extrasynthese (Genay, France). Trolox (6-hydroxy-2,5,7,8-tetramethylchroman-2-carboxylic acid) was purchased from Sigma Chemical Co. (St. Louis, MO, USA). Water was treated in a Milli-Q water purification system (TGI Pure Water Systems, Greenville, SC, USA).

\subsection{Extraction procedure}

The extraction was performed by stirring the sample $(1 \mathrm{~g})$ with $30 \mathrm{~mL}$ of methanol/water $(80: 20, \mathrm{v} / \mathrm{v})$ at $25{ }^{\circ} \mathrm{C}$ and $150 \mathrm{rpm}$ for $1 \mathrm{~h}$, and filtered through Whatman no. 4 paper. The final residue was then extracted with an additional $30 \mathrm{~mL}$ portion of the extraction solvents mixture. The combined extracts were evaporated at $35{ }^{\circ} \mathrm{C}$ under reduced pressure (rotary evaporator Büchi R-210, Flawil, Switzerland) and then lyophilized (FreeZone 4.5, Labconco, Kansas City, MO, USA). The lyophilized extracts were re-dissolved in methanol/water $(80: 20, \mathrm{v} / \mathrm{v})$, performing a stock solution with a concentration of $20 \mathrm{mg} \mathrm{mL}^{-1}$, from which several dilutions were prepared.

\subsection{Analysis of phenolic compounds}

Phenolic compounds were determined by HPLC (HewlettPackard 1100, Agilent Technologies, Santa Clara, USA) as previously described by the authors. ${ }^{28}$ Double online detection was carried out in the diode array detector (DAD) using $280 \mathrm{~nm}$ and $370 \mathrm{~nm}$ as preferred wavelengths and in a mass spectrometer (MS) connected to the HPLC system via the DAD cell outlet. Peaks were tentatively identified based on their UV-vis and mass spectra and comparison with data reported in the literature. Quantification was performed from the areas of the peaks recorded at 280 and $370 \mathrm{~nm}$ using calibration curves (1-100 $\mu \mathrm{g} \mathrm{mL} \mathrm{mL}^{-1}$ ) obtained with phenolic standards of the same group. The results were expressed in $\mathrm{mg}$ per $\mathrm{g}$ of extract.

\subsection{Evaluation of antioxidant activity}

2.5.1. DPPH radical-scavenging activity (RSA) assay. The capacity to scavenge the "stable" free radical DPPH, monitored according to the method of Hatano et al., with some modifications, ${ }^{29}$ was performed by using an ELX800 Microplate Reader (Bio-Tek Instruments, Inc; Winooski, USA). The reaction mixture in each one of the 96-wells consisted of one of the different concentration solutions $(30 \mu \mathrm{L})$ and methanolic solution $(270 \mu \mathrm{L})$ containing DPPH radicals $\left(6 \times 10^{-5} \mathrm{~mol} \mathrm{~L}^{-1}\right)$. The mixture was left to stand for $30 \mathrm{~min}$ in the dark. The reduction of the DPPH radical was determined by measuring the absorption at $515 \mathrm{~nm}$. The radical scavenging activity (RSA) was calculated as a percentage of DPPH discolouration using the equation: $\operatorname{RSA}(\%)=\left[\left(A_{\mathrm{DPPH}}-A_{\mathrm{S}}\right) / A_{\mathrm{DPPH}}\right] \times 100$, where $A_{\mathrm{S}}$ is the absorbance of the solution when the sample extract has been added at a particular level, and $A_{\mathrm{DPPH}}$ is the absorbance of the DPPH solution. The extract concentration providing $50 \%$ of antioxidant activity $\left(\mathrm{EC}_{50}\right)$ was calculated from the graph of DPPH scavenging activity against extract concentrations. Trolox was used as positive control.

2.5.2. Reducing power (RP) assay. RP was determined according to the method of Oyaizu, with some modifications. ${ }^{30}$ The present methodology is based on the capacity to convert $\mathrm{Fe}^{3+}$ into $\mathrm{Fe}^{2+}$, measuring the absorbance at $690 \mathrm{~nm}$, by using the microplate Reader mentioned above. At the different concentration solutions $(0.5 \mathrm{~mL})$ were added sodium phosphate buffer (200 mmol L ${ }^{-1}$, pH 6.6, $0.5 \mathrm{~mL}$ ) and potassium ferricyanide $(1 \% \mathrm{w} / \mathrm{v}, 0.5 \mathrm{~mL})$. The mixture was incubated at $50{ }^{\circ} \mathrm{C}$ for $20 \mathrm{~min}$, and then, trichloroacetic acid $(10 \% \mathrm{w} / \mathrm{v}$, $0.5 \mathrm{~mL})$ was added. In a 48-wells, the obtained mixture $(0.8 \mathrm{~mL})$, and also deionised water $(0.8 \mathrm{~mL})$ and ferric chloride $(0.1 \% \mathrm{w} / \mathrm{v}, 0.16 \mathrm{~mL})$ was joined, and the absorbance was measured at $690 \mathrm{~nm}$. The extract concentration providing 0.5 of absorbance $\left(\mathrm{EC}_{50}\right)$ was calculated from the graph of absorbance at $690 \mathrm{~nm}$ against extract concentrations. Trolox was used as positive control.

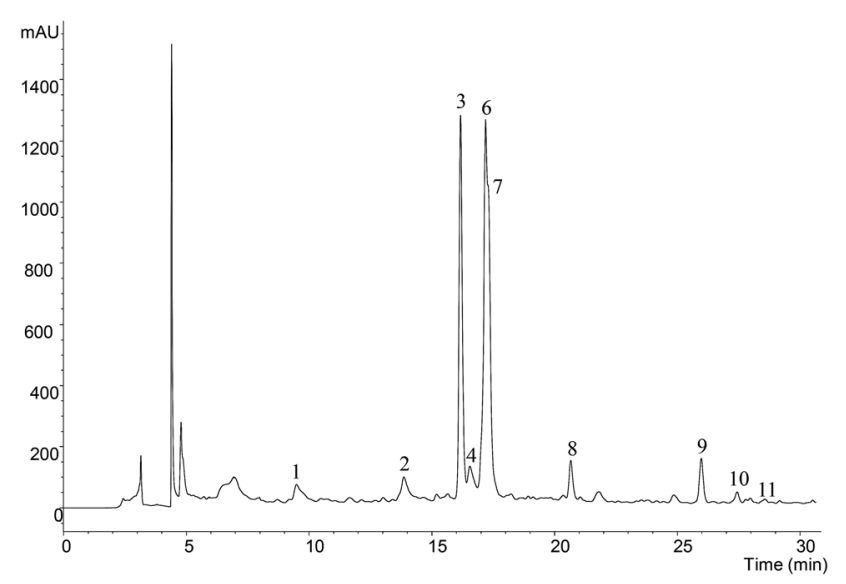

(A)

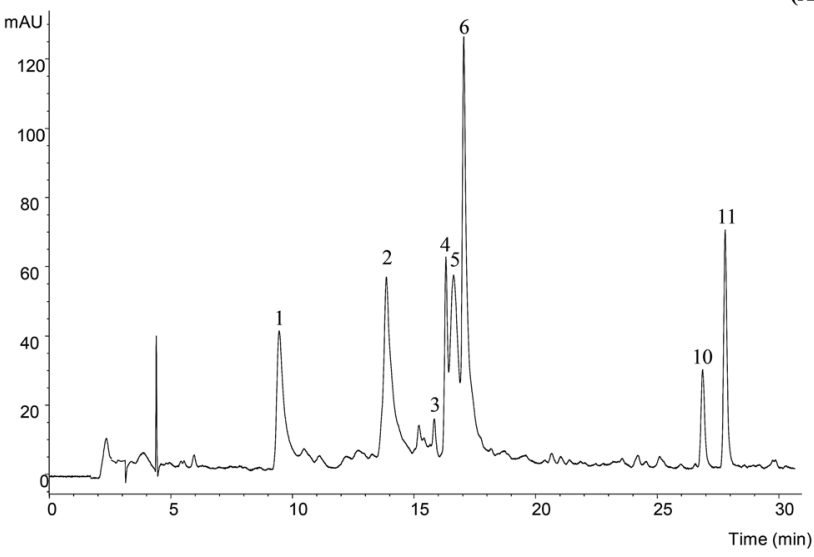

(B)

Fig. 1 Phenolic profile of Glycyrrhiza glabra L. methanol/water extract at $280 \mathrm{~nm}(\mathrm{~A})$ and $370 \mathrm{~nm}$ (B). 

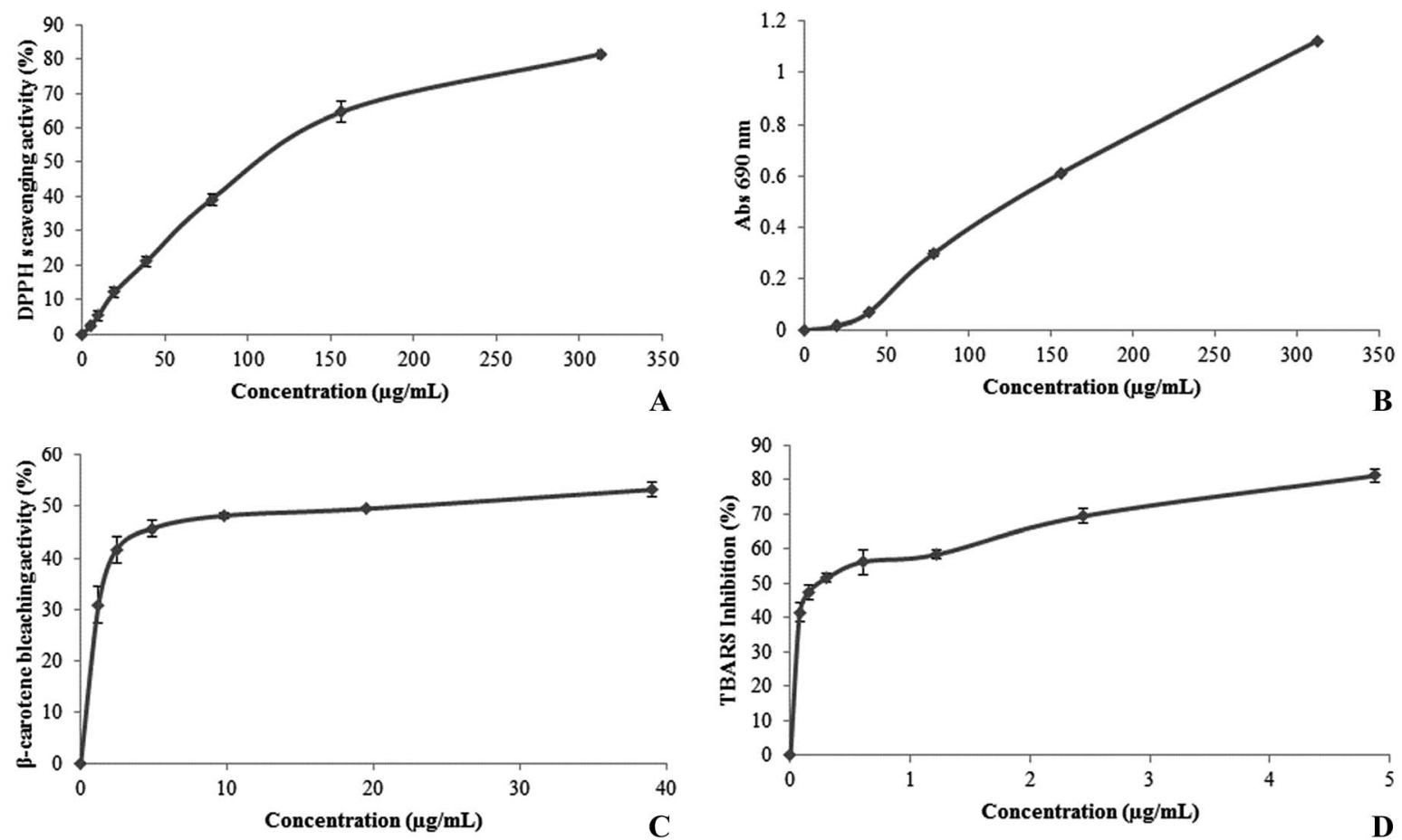

Fig. 2 Antioxidant activity of the G. glabra methanol/water extract evaluated by (A) DPPH scavenging activity $\left(\mathrm{EC}_{50}=111.54 \pm 6.04 \mu \mathrm{g} \mathrm{mL}^{-1}\right)$, (B) reducing power $\left(\mathrm{EC}_{50}=128.63 \pm 0.21 \mu \mathrm{g} \mathrm{mL}-1\right.$ ), (C) $\beta$-carotene bleaching activity $\left(22.74 \pm 2.42 \mu \mathrm{g} \mathrm{mL} \mathrm{L}^{-1}\right)$ and (D) TBARS inhibition $\left(0.24 \pm 0.01 \mu \mathrm{g} \mathrm{mL}{ }^{-1}\right)$.

2.5.3. $\quad \beta$-Carotene bleaching inhibition (CBI) assay. CBI was evaluated though the $\beta$-carotene/linoleate assay. A solution of $\beta$-carotene was prepared by dissolving $\beta$-carotene $(2 \mathrm{mg})$ in chloroform $(10 \mathrm{~mL})$. Two millilitres of this solution were pipetted into a round-bottom flask. After the chloroform was removed at $40{ }^{\circ} \mathrm{C}$ under vacuum, linoleic acid ( $40 \mathrm{mg}$ ), Tween 80 emulsifier ( $400 \mathrm{mg})$, and distilled water $(100 \mathrm{~mL})$ were added to the flask with vigorous shaking. Aliquots $(4.8 \mathrm{~mL})$ of the obtained emulsion were transferred into different test tubes containing different concentrations of the samples $(0.2 \mathrm{~mL})$. The tubes were shaken and incubated at $50{ }^{\circ} \mathrm{C}$ in a water bath. As soon as the emulsion was added to each tube, the zero time absorbance was measured at $470 \mathrm{~nm}$ in a spectrophotometer (AnalytikJena, Jena, Germany). $\beta$-Carotene bleaching inhibition was calculated using the following equation: (Abs after $2 \mathrm{~h}$ of assay/initial Abs) $\times 100 .{ }^{31}$ The extract concentration providing $50 \%$ of antioxidant activity $\left(\mathrm{EC}_{50}\right)$ was calculated from the graph of $\beta$-carotene bleaching inhibition against extract concentrations. Trolox was used as positive control (Fig. 2).

2.5.4. Lipid peroxidation inhibition (LPI) through thiobarbituric acid reactive substances (TBARS) assay. LPI was evaluated by the decreasing in thiobarbituric acid reactive substances (TBARS). Porcine brains were obtained from official slaughtering animals, dissected, and homogenized with a Polytron in ice-cold Tris-HCl buffer $(20 \mathrm{mM}, \mathrm{pH} 7.4)$ to produce a $1: 2(\mathrm{w} / \mathrm{v})$ brain tissue homogenate, which was centrifuged at $3000 \mathrm{~g}$ for $10 \mathrm{~min}$. An aliquot $(0.1 \mathrm{~mL})$ of the supernatant was incubated with the different solution concentrations $(0.2 \mathrm{~mL})$ in the presence of $\mathrm{FeSO}_{4}(10 \mu \mathrm{M} ; 0.1 \mathrm{~mL})$ and ascorbic acid
( $0.1 \mathrm{mM} ; 0.1 \mathrm{~mL}$ ) at $37^{\circ} \mathrm{C}$ for $1 \mathrm{~h}$. The reaction was stopped by the addition of trichloroacetic acid $(28 \% \mathrm{w} / \mathrm{v}, 0.5 \mathrm{~mL})$, followed by thiobarbituric acid (TBA, 2\%, w/v, $0.38 \mathrm{~mL}$ ), and the mixture was then heated at $80{ }^{\circ} \mathrm{C}$ for $20 \mathrm{~min}$. After centrifugation at $3000 \mathrm{~g}$ for $10 \mathrm{~min}$ to remove the precipitated protein, the colour intensity of the malondialdehyde (MDA)-TBA complex in the supernatant was measured by its absorbance at $532 \mathrm{~nm}$. The inhibition ratio (\%) was calculated using the following formula: inhibition ratio $(\%)=[(A-B) / A] \times 100 \%$, where $A$ and $B$ were the absorbance of the control and the compound solution, respectively. ${ }^{32}$ The extract concentration providing $50 \%$ of antioxidant activity $\left(\mathrm{EC}_{50}\right)$ was calculated from the graph of TBARS formation inhibition against extract concentrations. Trolox was used as positive control.

\section{Results and discussion}

\subsection{Characterization of the phenolic compounds}

The phenolic profile of Glycyrrhiza glabra, obtained after methanol/water extraction, and recorded at 280 and $370 \mathrm{~nm}$ is shown in Fig. 1; compound characteristics and tentative identities are presented in Table 1. Eleven compounds were detected corresponding to the groups of flavones, flavanones and chalcones, as well as a possible isoflavone.

Compound 1 presented a pseudomolecular ion $[\mathrm{M}-\mathrm{H}]^{-}$at $\mathrm{m} / \mathrm{z}$ 593, releasing $\mathrm{MS}^{2}$ fragment ions at $\mathrm{m} / \mathrm{z} 443$ (loss of $120 \mathrm{u}$ ), 383 (apigenin $+113 \mathrm{u}$ ) and 353 (apigenin $+83 \mathrm{u}$ ), whereas no relevant fragments derived from the loss of complete hexosyl $(-162 \mathrm{u})$ or pentosyl residues $(-132 \mathrm{u})$ were detected. This 
Table 1 Retention time $\left(R_{\mathrm{t}}\right)$, wavelengths of maximum absorption in the visible region $\left(\lambda_{\text {max }}\right)$, mass spectral data, identification and quantification of phenolic compounds in Glycyrrhiza glabra methanol/water extract ${ }^{a}$

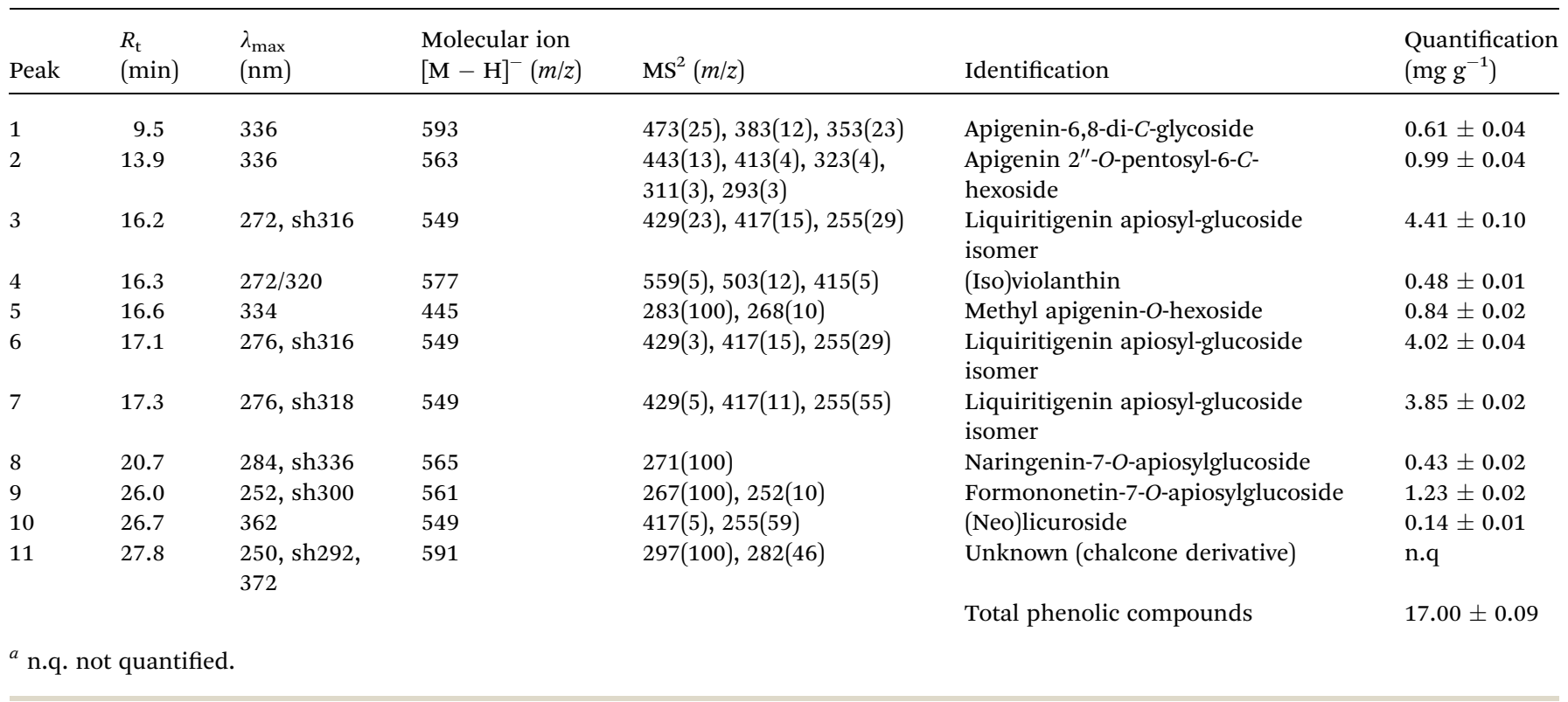

fragmentation behaviour is characteristic of di-C-glycosylated flavones. ${ }^{33}$ The compound was tentatively identified as apigenin-6,8-di-C-glucoside (vicenin-2) owing to its previous description in Traditional Chinese Medicine Formulae containing Glycyrrhiza roots and rhizomes. ${ }^{34,35}$

Compound 2 presented a pseudomolecular ion $[\mathrm{M}-\mathrm{H}]^{-}$at $\mathrm{m} / \mathrm{z}$ 563. A compound with the same mass was reported in licorice (dried roots and rhizomes of Glycyrrhiza species) by $\mathrm{Xu}$ et al. (2013) and identified as the di-C-glycosylflavone isoschaftoside (i.e., 6-C-arabinopyranosyl-8-C-glucopyranosylapigenin). However, the $\mathrm{MS}^{2}$ fragmentation pattern of the compound observed in our samples would not match such a structure, but it points to the pentosyl residue is $O$-attached to a $C$-glycosylating hexose. This assumption is supported by the characteristic fragment detected at $m / z 413\left([\mathrm{M}-150]^{-}\right)$, which according to ${ }^{33}$ would be typical from that type of substitution. Further, the fragment ion at $m / z 443\left([\mathrm{M}-120]^{-}\right)$supported the presence of a $C$-attached hexose, whilst the absence of an ion $[(\mathrm{M}-\mathrm{H})-90]^{-}$suggested a 6-C attachment. ${ }^{33}$ The pentose should not be attached on positions $6^{\prime \prime}, 4^{\prime \prime}$ or $3^{\prime \prime}$ of the hexose, otherwise the fragment $[(\mathrm{M}-\mathrm{H})-120]^{-}$would not be produced. As for the rest of fragment ions, the one at $m / z 323[(\mathrm{M}-\mathrm{H})-150$ $-90]^{-}$would result from the partial loss of the $C$-attached hexose from the ion at $m / z 413$, whereas those at $m / z 311$ [aglycone +41$]^{-}$ and 293 [aglycone $+41-18]^{-}$are associated to mono- $C$-glycosyl derivatives $O$-glycosylated on $2^{\prime \prime}{ }^{36} \mathrm{All}$ in all, peak 2 was tentatively assigned as apigenin $2^{\prime \prime}$-O-pentosyl-6-C-hexoside.

Compound 4 showed a pseudomolecular ion $\left([\mathrm{M}-\mathrm{H}]^{-}\right.$at $m / z$ 577) and a UV spectrum coherent the $C$-glycosylflavones commonly reported in Glycyrrhiza species isoviolanthin (apigenin-6- $C$-rhamnoside-8-C-glucoside) (4, $35,37-39^{3}$ or violanthin (apigenin-6- $C$-glucoside-8- $C$-rhamnoside). ${ }^{34,35}$ The data obtained in this study do not allow to conclude about the precise pattern of sugar substitution, so that the compound was just identified as (iso) violanthin. Compound 5 also corresponded to another flavone that was tentatively assigned as a methylapigenin $O$-hexoside based on its UV and mass spectral data.

Compounds 3, 6, 7 and 10 presented the same pseudomolecular ion $[\mathrm{M}-\mathrm{H}]^{-}$at $\mathrm{m} / \mathrm{z} 549$, all of them releasing a main $\mathrm{MS}^{2}$ fragment at $m / z 255$, from the loss of $132+162 \mathrm{u}$ (pentosyl + hexosyl residues), pointing to the correspond different apiosylglucosides of (iso)liquiritigenin, consistently reported to occur as major flavonoids in licorice. ${ }^{34,35,37-43}$ The fragmentation patterns do not allow to distinguish between liquiritigenin (a flavanone) and isoliquiritigenin (a chalcone), so that they were assigned as derived from one or another based on their UV spectra, showing maxima at $272-276 \mathrm{~nm}$ plus a shoulder around 316-318 nm (peaks 3, 6 and 7) or $362 \mathrm{~nm}$ (peak 10), respectively. Liquiritin apioside (i.e., liquiritigenin $4^{\prime}$-O-apiosylglucoside) has been widely reported to occur in Glycyrrhiza species, ${ }^{34,35,37-45}$ although other isomers have also been described, such as liquiritigenin 7-O-apiosyl-glucoside ${ }^{40,42,43}$ and liquiritigenin-7-O-apiosyl-4'-O-glucoside. ${ }^{34}$ The results obtained herein do not allow concluding about the precise location of the sugar moieties, so that they were just identified as liquiritigenin apiosyl-glucoside isomers. Furthermore, as the carbon at position 2 is asymmetric the possibility of different stereoisomers may be also envisaged.

As previously indicated, compound 10 should correspond to a derivative of the chalcone isoliquiritigenin bearing pentosyl + hexosyl residues. Two main isomers possessing that structure have been widely reported in Glycyrrhiza species: licuroside (also designed as licuraside; isoliquiritigenin- $4^{\prime}-O$-apiosylglucoside) and neolicuroside (isoliquiritigenin-4-O-apiosylglucoside). ${ }^{34,35,37,39,41-43,45}$ As for the liquiritigenin derivatives, it was not possible to conclude about the precise location of the 
glycosyl groups, so that compound 10 was assigned as (neo) licuroside.

Compound 8 presented a pseudomolecular ion $[\mathrm{M}-\mathrm{H}]^{-}$at $\mathrm{m} / z 565$ releasing a fragment ion at $\mathrm{m} / \mathrm{z} 271(-294 \mathrm{u}$, loss of a pentosyl and hexosyl moieties), and a UV spectrum coherent with a flavanone. These characteristics match the structure of naringenin-7-O-apiosyl-glucoside reported in radix Glycyrrhizae by Wang et al. (2014), so that this identity was tentatively assumed for the compound.

Compound $9\left([\mathrm{M}-\mathrm{H}]^{-}\right.$at $\left.m / z 561\right)$ was tentatively identified as glycyroside (i.e., formononetin-7-O-apiosylglucoside) owing to the previous identification of that isoflavone in radix Glycyrrhizae by Wang et al. (2014). The presence of formononetin derivatives in Glycyrrhiza species has also been reported by various authors. ${ }^{35,41,42,45,46}$

Finally, it was not possible to identify compound 11 with a pseudomolecular ion $[\mathrm{M}-\mathrm{H}]^{-}$at $\mathrm{m} / z 591$ that released two fragments at $m / z 297(-294$, loss of a pentosyl and hexosyl moieties) and 282 (further loss of $-15 \mathrm{u}$ of a methyl residue), although its UV spectra with a maximum at $372 \mathrm{~nm}$ pointed to a chalcone aglycone.

Among the eleven phenolic compounds detected, liquiritin apioside isomers were the most abundant. Many papers have been published profiling phenolic compounds in G. glabra samples from different origins and using different extraction methodologies, some of them cited in the previous discussion. ${ }^{34,35,37-46}$ However, from all of them, only Montoro et al. (2011) presented quantitative results, although they cannot be compared with ours results since they are expressed differently (mg $\mathrm{g}^{-1}$ of dry plant), thus these authors revealed liquiritin apioside as the main flavonoid present in their sample, which is in agreement with the sample studied herein. In our case, the results were expressed in $\mathrm{mg} \mathrm{g}^{-1}$ of extract in order to relate the amounts of phenolic compounds found in the extract to the antioxidant activity. Therefore this study will add new data related to the quantification of these compounds, which are scarce in literature.

\subsection{Evaluation of antioxidant activity}

Fig. 1 shows the results of the antioxidant potential of the licorice extract using different assays: DPPH radical scavenging activity (RSA), reducing power (RP), $\beta$-carotene bleaching inhibition (CBI) and lipid peroxidation inhibition (LPI) in brain cell homogenates. The most pronounced effect was observed for LPI assay $\left(\mathrm{EC}_{50}=0.24 \pm 0.01 \mu \mathrm{g} \mathrm{mL} \mathrm{mL}^{-1}\right)$, followed by CBI $\left(\mathrm{EC}_{50}=22.74 \pm 2.42 \mu \mathrm{g} \mathrm{mL}{ }^{-1}\right)$. RSA and RP presented higher $\mathrm{EC}_{50}$ values (meaning lower antioxidant activity), respectively, $111.54 \pm 6.04 \mu \mathrm{g} \mathrm{mL}^{-1}$ and $128.63 \pm 0.21 \mu \mathrm{g} \mathrm{mL}^{-1}$.

The LPI capacity, accessed by using the TBARS assay, measures the malondialdehyde (MDA) formed as the split product of an endoperoxide of unsaturated fatty acids resulting from oxidation of a lipid substrate. The MDA is reacted with thiobarbituric acid (TBA) to form a pink pigment (TBARS) that is measured spectrophotometrically at $532 \mathrm{~nm} .{ }^{32}$

$$
\mathrm{MDA}+\mathrm{TBA} \rightarrow \mathrm{MDA}-\mathrm{TBA}_{2}
$$

$$
\mathrm{MDA}+\mathrm{TBA}+\mathrm{A} \rightarrow \mathrm{MDA}+\mathrm{TBA}_{2}
$$

This procedure involves two distinct steps: the substrate is oxidized with the addition of a transition metal ion such as copper or iron or a free radical source such as 2,2 '-azobis (2-amidinopropane) dihydrochloride, and then the extent of oxidation is determined by addition of TBA and spectrophotometric measurement of the product $\left(\mathrm{MDA}-\mathrm{TBA}_{2}\right)$. Oxidation is inhibited by the addition of an antioxidant and, therefore, a reduction in the absorbance is observed. In the present experiment, the studied methanol/water extract exerted strong inhibitory effects of lipid oxidation (e.g., exponential inhibition of TBARS formation, being these effects achieved at extremely low concentrations), which is in agreement with the results obtained by Jiang et al. ${ }^{47}$ that reported the efficacy of licorice ethanolic extract to prevent lipid oxidation and protect sensory attributes of ground pork.

Concerning to the CBI assay, and taking into account the basis of the method, $\beta$-carotene undergoes a rapid discoloration in the absence of an antioxidant since the free linoleic acid radical attacks the $\beta$-carotene molecule, which loses the double bonds and, consequently, loses its characteristic orange colour. Antioxidants can donate hydrogen atoms to quench radicals and prevent decolourization of carotenoids, ${ }^{48}$ through the following reactions: $\beta$-carotene- $\mathrm{H}$ (orange) $+\mathrm{ROO}^{*} \rightarrow \beta$-carotene ${ }^{\bullet}$ (bleached) $+\mathrm{ROOH} \beta$-carotene- $\mathrm{H}$ (orange) $+\mathrm{ROO}^{\bullet}+\mathrm{AH}$ $\rightarrow \beta$-carotene- $\mathrm{H}$ (orange) $+\mathrm{ROOH}+\mathrm{A}^{*}$

The decolourization of $\beta$-carotene can be monitored by spectrophotometry at $470 \mathrm{~nm} .{ }^{49}$ Regarding the obtained results for the CBI activity of the studied methanol/water extract, a more pronounced effect $\left(\mathrm{EC}_{50}=23 \mu \mathrm{g} \mathrm{mL}{ }^{-1}\right)$ was observed than the one reported by Ercisli et al. (2008) for ethanolic extracts of licorice roots collected in Turkey $\left(\mathrm{EC}_{58}=75 \mu \mathrm{g} \mathrm{mL}{ }^{-1}\right)$. The results reported by these authors ranged between $28.3 \%$ $\left(25 \mu \mathrm{g} \mathrm{mL}^{-1}\right)$ and $88.7 \%\left(800 \mu \mathrm{g} \mathrm{mL}^{-1}\right)$.

2,2-Diphenyl-1-picrylhydrazyl radical (DPPH), a stable organic nitrogen radical which presents a deep purple colour, allows the determination and quantification of the reducing capacity of antioxidants toward DPPH. Representing the DPPH radical by $\mathrm{X}^{*}$ and the donor molecule by $\mathrm{AH}$ (being mainly phenolic compounds, they are proton donators), the primary reaction is:

$$
\mathrm{X}^{\bullet}+\mathrm{AH} \rightarrow \mathrm{XH}+\mathrm{A}^{\bullet}
$$

In the present reaction, $\mathrm{XH}$ is the reduced form and $\mathrm{A}^{\circ}$ is the free radical produced in this first step. This latter radical will then undergo further reactions, which control the overall stoichiometry, that is, the number of molecules of DPPH reduced (decolorized) by one molecule of the reductant. ${ }^{50}$ When a solution of $\mathrm{DPPH}^{\circ}$ is mixed with a substance that can donate a hydrogen atom, the reduced form of the radical is generated accompanied by loss of colour. Upon reduction, the colour of $\mathrm{DPPH}^{*}$ solution fades and this colour change is conveniently monitored measuring the absorbance decrease at 515-528 
nm. ${ }^{51}$ Thus, by using the present assay, the free radicals scavenger effect of licorice was accessed. The RSA obtained for the studied methanol/water extract $\left(\mathrm{EC}_{50}=112 \mu \mathrm{g} \mathrm{mL} \mathrm{mL}^{-1}\right)$ was similar to some of the values reported by Cheel et al. (2012) for similar extracts prepared from samples harvested at different times (February - $\mathrm{EC}_{70}=100 \mu \mathrm{g} \mathrm{mL}^{-1}$, May $-\mathrm{EC}_{60}=30$ $\mu \mathrm{g} \mathrm{mL}^{-1}$, August $-\mathrm{EC}_{50}=50 \mu \mathrm{g} \mathrm{\textrm {mL } ^ { - 1 }}$, November $-\mathrm{EC}_{50}=30$ $\mu \mathrm{g} \mathrm{mL}^{-1}$ ), and by Cheel et al. (2010) for extracts obtained by infusion $\left(\mathrm{EC}_{49}=100 \mu \mathrm{g} \mathrm{mL}{ }^{-1}\right)$. However, it was lower than the RSA described by Tohma \& Gulçin (2010) for aqueous $\left(\mathrm{EC}_{52}=62\right.$ $\left.\mu \mathrm{g} \mathrm{mL}^{-1}\right)$ and ethanol $\left(\mathrm{EC}_{54}=50 \mu \mathrm{g} \mathrm{mL}^{-1}\right)$ extracts obtained from roots of Turkish licorice samples.

RP assay, widely used due to its specificity to access the electron-donating potential of antioxidants, and consequent reduction of yellow ferric form to blue ferrous form. ${ }^{52,53}$ Antioxidant species $\mathrm{Fe}(\mathrm{III})$ or $\mathrm{Fe}(\mathrm{CN})_{6}{ }^{3-}$, when in the present of composite ferricyanide reagent, favors its reduction, and either $\mathrm{Fe}(\mathrm{II})$ or $\mathrm{Fe}(\mathrm{CN})_{6}{ }^{4-}$ is formed, and combining with a reagent component - Prussian blue, $\mathrm{KFe}\left[\mathrm{Fe}(\mathrm{CN})_{6}\right]$, a coloured product is produced. In this sense, by using $\mathrm{Fe}^{3+}$ in conjunction with $\mathrm{Fe}(\mathrm{CN})_{6}{ }^{3-}$, while oxidizing agent, any of the follow two reaction pair could occurs, despite the ending coloured product to be the same: ${ }^{54}$

$$
\begin{gathered}
\mathrm{Fe}^{3+}+\text { antioxidant } \leftrightarrows \mathrm{Fe}^{2+}+\text { oxidized antioxidant } \\
\mathrm{Fe}^{2+}+\mathrm{Fe}(\mathrm{CN})_{6}{ }^{3-} \leftrightarrows \mathrm{Fe}\left[\mathrm{Fe}(\mathrm{CN})_{6}\right]^{-}
\end{gathered}
$$

The resultant blue colour is linearly correlated with the total reducing potential of electron-donating antioxidants, being measured spectrophotometrically at $700 \mathrm{~nm} .{ }^{55}$ The RP value obtained in the present study $\left(\mathrm{EC}_{50}=129 \mu \mathrm{g} \mathrm{mL}^{-1}\right)$ was similar to the one described by Tohma \& Gulçin (2010) for aqueous $\left(\mathrm{EC}_{45}=62 \mathrm{mg} \mathrm{mL}{ }^{-1}\right)$ and ethanolic $\left(\mathrm{EC}_{76}=50 \mathrm{mg} \mathrm{mL} \mathrm{m}^{-1}\right)$ extracts.

Numerous reports have confirmed the association between phenolic compounds and bioactive properties. Regarding G. glabra, flavonoids saponins, coumarins, and stilbenoids have been related with its bioactive properties. Until now, licochalcone A, B, C, D and echinatin, some isoflavones and derivatives, such as glabridin, an isoflavan, hispaglabridin A, hispaglabridin B and 4'-O-methylglabridin, but also some chalcones, namely isoprenylchalcone derivative and isoliquiritigenin, were described as possessing potent antioxidant effects, not only inhibiting lipid peroxidation but also acting as radical scavengers and oxidative process preventers. ${ }^{18,27,56,57}$ Regarding our study, it is feasible to attribute the antioxidant potential observed for the tested extract to the most abundant phenolic compounds identified, namely liquiritigenin apiosylglucosides. Nevertheless, it is important to highlight that plant extracts are usually much more effective than isolated compounds, as it was proved by Cheel et al. (2010) for the case of licorice aqueous extract. The authors verified that, despite in some assays licorice extract evidenced a weak antioxidant activity, the major components identified (liquiritin and glycyrrhizin) presented negligible or even no effects.
Overall, licorice extract could be used as a source of antioxidants for pharmaceutical, cosmetic and/or food industries. Regarding its antioxidants contribution in daily diet, further studies are necessary in order to elucidate the mechanisms of in vivo antioxidant action, bioavailability and involved metabolic pathways.

\section{Acknowledgements}

The authors are grateful to Foundation for Science and Technology (FCT, Portugal) for N. Martins grant (SFRH/BD/87658/ 2012), L. Barros researcher contract under "Programa Compromisso com Ciência - 2008" and financial support to the research center CIMO (strategic project PEst-OE/AGR/UI0690/ 2011).

\section{References}

1 M. Valko, D. Leibfritz, J. Moncol, M. T. D. Cronin, M. Mazur and J. Telser, Int. J. Biochem. Cell Biol., 2007, 39, 44-84.

2 R. K. Chaturvedi and M. F. Beal, Free Radical Biol. Med., 2013, 63, 1-29.

3 M. Gilca, I. Stoian, V. Atanasiu and B. Virgolici, J. Postgrad. Med., 2007, 53, 207-213.

4 E. Agradi, E. Vegeto, A. Sozzi, G. Fico, S. Regondi and F. Tomè, Phytother. Res., 2006, 20, 670-675.

5 E. A. Palombo, J. Evidence-Based Complementary Altern. Med., 2011, 2011, 1-15.

6 R. R. Mendonça-Filho, in Modern Phytomedicine. Turning Medicinal Plants into Drugs, Wiley-VCH, 2006, pp. 1-24.

7 J. Cheel, P. Van Antwerpen, L. Tůmová, G. Onofre, D. Vokurková, K. Zouaoui-Boudjeltia, M. Vanhaeverbeek and J. Nève, Food Chem., 2010, 122, 508-517.

8 R. P. Singh, S. Sharad and S. Kapur, J. Indian Acad. Clin. Med., 2004, 5, 218-225.

9 M. Carocho and I. C. F. R. Ferreira, Food Chem. Toxicol., 2013, 51, 15-25.

10 M. Carocho and I. C. F. R. Ferreira, Anti-Cancer Agents Med. Chem., 2013, 13, 1236-1258.

11 B. Halliwell, Nutr. Rev., 2012, 70, 257-265.

12 L. Rubió, M.-J. Motilva and M.-P. Romero, Crit. Rev. Food Sci. Nutr., 2013, 53, 943-953.

13 J. Dai and R. J. Mumper, Molecules, 2010, 15, 7313-7352.

14 J. S. Ramkissoon, M. F. Mahomoodally, N. Ahmed and A. H. Subratty, Asian Pac. J. Trop. Med., 2013, 6, 561-569.

15 G. Calapai and M. Delbò, Eur. Med. Agency - Sci. Med. Heal., 2012, 1-40.

16 V. S. Jatav, S. K. Singh, P. Khatri and A. K. Sharma, Int. J. Pharm. Res., 2011, 1, 170-185.

17 M. T. Murray, The healing power of herbs, Random House, New York, NY, 2nd edn, 2004.

18 R. Kaur, H. Kaur and A. S. Dhindsa, Int. J. Pharma Sci. Res., 2013, 4, 2470-2477.

19 G. H. Naik, K. I. Priyadarsini, J. G. Satav, M. M. Banavalikar, D. P. Sohoni, M. K. Biyani and H. Mohan, Phytochemistry, 2003, 63, 97-104. 
20 H. S. Tohma and I. Gulçin, Int. J. Food Prop., 2010, 13, 657671.

21 J. Vaya, P. A. Belinky and M. Aviram, Free Radical Biol. Med., 1997, 23, 302-313.

22 S. Ercisli, I. Coruh, A. Gormez, M. Sengul and S. Bilen, Ital. J. Food Sci., 2008, 20, 91-100.

23 I. Khalaf, L. Vlase, D. Lazãr, A. Corciovã, B. Ivãnescu and M. I. Lazãr, Farmacia, 2010, 58, 416-421.

24 L. Siracusa, A. Saija, M. Cristani, F. Cimino, M. D'Arrigo, D. Trombetta, F. Rao and G. Ruberto, Fitoterapia, 2011, 82, 546-556.

25 S. D. Angelo, A. Morana, A. Salvatore, V. Zappia and P. Galletti, J. Med. Food, 2009, 12, 1326-1333.

26 Y.-J. Li, J. Chen, Y. Li, Q. Li, Y.-F. Zheng, Y. Fu and P. Li, J. Chromatogr. A, 2011, 1218, 8181-8191.

27 J. Cheel, L. Tůmová, C. Areche, P. Van Antwerpen, J. Nève, K. Zouaoui-Boudjeltia, A. S. Martin, I. Vokřál, V. Wsól and J. Neugebauerová, Acta Physiol. Plant., 2012, 35, 1337-1349.

28 L. Barros, C. T. Alves, M. Dueñas, S. Silva, R. Oliveira, A. M. Carvalho, M. Henriques, C. Santos-Buelga and I. C. F. R. Ferreira, Ind. Crops Prod., 2013, 44, 104-110.

29 T. Hatano, H. Kagawa, T. Yasuhara and T. Okuda, Chem. Pharm. Bull., 1988, 36, 2090-2097.

30 M. Oyaizu, Jpn. J. Nutr., 1986, 44, 307-315.

31 S. Mi-Yae, K. Tae-Hun and S. Nak-Ju, Food Chem., 2003, 82, 593-597.

32 T. B. Ng, F. Liu and Z. Wang, Life Sci., 2000, 66, 709-723.

33 F. Ferreres, B. M. Silva, P. B. Andrade, R. M. Seabra and M. A. Ferreira, Phytochem. Anal., 2003, 14, 352-359.

34 S. Wang, L. Chen, J. Leng, P. Chen, X. Fan and Y. Cheng, J. Pharm. Biomed. Anal., 2014, 98, 22-35.

35 Q. Yin, P. Wang, A. Zhang, H. Sun, X. Wu and X. Wang, J. Sep. Sci., 2013, 36, 1238-1246.

36 F. Ferreres, C. Sousa, P. Valentão, P. B. Andrade, R. M. Seabra and Á. Gil-Izquierdo, J. Agric. Food Chem., 2007, 55, 1018710193.

37 M. A. Farag, A. Porzel and L. A. Wessjohann, Phytochemistry, 2012, 76, 60-72.

38 P. Montoro, M. Maldini, M. Russo, S. Postorino, S. Piacente and C. Pizza, J. Pharm. Biomed. Anal., 2011, 54, 535-544.

39 Y. Wang, S. He, X. Cheng, Y. Lu, Y. Zou and Q. Zhang, J. Pharm. Biomed. Anal., 2013, 80, 24-33.
40 W. C. Liao, Y.-H. Lin, T.-M. Chang and W.-Y. Huang, Food Chem., 2012, 132, 2188-2193.

41 X. Qiao, M. Ye, C. Xiang, Q. Wang, C.-F. Liu, W.-J. Miao and D. Guo, J. Chromatogr. A, 2012, 1258, 84-93.

42 T. Xu, M. Yang, Y. Li, X. Chen, Q. Wang, W. Deng, X. Pang, K. Yu, B. Jiang, S. Guan and D. Guo, Rapid Commun. Mass Spectrom., 2013, 27, 2297-2309.

43 C. Simmler, T. Jones, J. R. Anderson, D. C. Nikolić, R. B. van Breemen, D. D. Soejarto, S.-N. Chen and G. F. Pauli, Phytochem. Anal., 2014, 25, 378-388.

44 M. Ye, S.-H. Liu, Z. Jiang, Y. Lee, R. Tilton and Y.-C. Cheng, Rapid Commun. Mass Spectrom., 2007, 21, 3593-3607.

45 R. Simons, J.-P. Vincken, E. J. Bakx, M. A. Verbruggen and H. Gruppen, Rapid Commun. Mass Spectrom., 2009, 23, 3083-3093.

46 J. Xie, W. Wang, Y. Zhang, Y. Bai and Q. Yang, J. Pharm. Biomed. Anal., 2007, 45, 450-455.

47 J. Jiang, X. Zhang, A. D. True, L. Zhou and Y. L. Xiong, J. Food Sci., 2013, 78, C1686-C1694.

48 I. P. Kaur and T. Geetha, Mini-Rev. Med. Chem., 2006, 6, 305312.

49 A. R. Ndhlala, M. Moyo and J. V. Staden, Molecules, 2010, 15, 6905-6930.

50 P. Molyneux, Songklanakarin J. Sci. Technol., 2004, 26, 211219.

51 A. Karadag, B. Ozcelik and S. Samim, Food Analytical Methods, 2009, 2, 41-60.

52 I. F. F. Benzie, W. Y. Chung and J. J. Strain, J. Nutr. Biochem., 1999, 10, 146-150.

53 F. S. Reis, A. Martins, L. Barros and I. C. F. R. Ferreira, Food Chem. Toxicol., 2012, 50, 1201-1207.

54 K. I. Berker, K. Güçlü, I. Tor and R. Apak, Talanta, 2007, 72, 1157-1165.

55 D. Huang, B. Ou and R. L. Prior, J. Agric. Food Chem., 2005, 53, 1841-1856.

56 M. N. Asl and H. Hosseinzadeh, Phytother. Res., 2008, 22, 709-724.

57 Y. W. Chin, H. A. Jung, Y. Liu, B. N. Su, J. A. Castoro, W. J. Keller, M. A. Pereira and A. D. Kinghorn, J. Agric. Food Chem., 2007, 55, 4691-4697. 